\title{
Temporal relationship between panic attack onset and phobic avoidance in agoraphobia
}

\author{
BRUCE A. ThyeR \\ School of Social Work, Florida State Unitersity, Tallahassee. FL 32306, U.S.A.
}

\author{
JOSEPH HIMLE \\ Deparment of Psychiary. The University of Michigan Hospitals, Ann Arbor, MI 48109. U.S.A.
}

(Received 30 January 1985)

\begin{abstract}
Summary-In a sample of 28 members of an agoraphobia self-help group, each patient reported a history of spontaneous panic attacks. The onset of panic attacks preceded the development of agoraphobic restrictions by an average of $9 \mathrm{yr}$, and $79_{;}^{\circ}$ of the sample attributed the development of their agoraphobia to their experience of panics. These results provide the first empirical support for the hypothesis that agoraphobia is secondary to panic attacks.
\end{abstract}

\section{INTRODUCTION}

The current edition of the Diagnostic and Statistical Manual (DSM-III) notes that in some cases of agoraphobia the disorder is accompanied by the experience of one or more apparently spontaneous panic attacks (APA, 1980, p. 226). In the other phobic disorders (simple and social phobia), the anxiety-evoking stimulus involves specific objects, animals or situations external to the individual. When the simple or social phobic is not in the presence of the anxiety-evoking stimulus, and does not anticipate such exposure, the patient is indistinguishable from the normal individual who does not suffer from pathological anxiety. In some cases of agoraphobia however. the situation is appreciably different. The occurrence of spontaneous panic attacks appears to be stimulus independent, inrelated to either identifiable environmental stimuli or cognitions. The DSM-III does not clearly specify the functional relationship occurring between panic attacks and agoraphobic avoidance behavior, although there has been considerable speculation. In 1894 for example, Freud noted that

"In the case of agoraphobia etc.. we often find the recollection of an anxiety attack; and what the patient fears is the occurrence of such an attack under the special conditions in which he believes he cannot escape it." (1962:1894. p. 81)

This important observation was rarely referred to in the clinical literature addressing agoraphobia until the resurrection of the hypothesis by Mendel and Klein (1969), who clearly stated that in the natural history of agoraphobia, phobic avoidance is a phenomenon secondary to the onset of spontaneous attacks of acute anxiety which strike the individual without warning. Typically, such an individual first develops fears of situations wherein panic attacks have occurred in the past. With the passage of time however, and repeated random episodes of panic, the individual comes to fear and avoid any situation where. if a panic attack occurred, immediate escape would be difficult or help unobtainable. When phobic avoidance comes to dominate the individual's life, the diagnosis of agoraphobja becomes applicable (APA, 1980).

Although this version of the natural history of agoraphobia is now commonly accepted (Klein. 1981; Sheehan. 1982; Sheehan and Sheehan. 1982; APA. 1980), empirical studies documenting the temporal relationship between the onset of panic attacks and the development of agoraphobic avoidance have not been conducted. In one series of 115 patients receiving a diagnosis of agoraphobia. $95\left(83_{\%}^{\circ}\right)$ met the criteria for agoraphobia with panic attacks, while the remaining $20(17 \%)$ were diagnosed as agoraphobia without panic attacks (Thyer, Parrish, Curtis, Cameron and Nesse, 1985). Although agoraphobia with panic attacks thus appeared to be the more commonly presented disorder, data on the relationships between the two components of the diagnosis were lacking. We undertook the following preliminary study to address this issue.

\section{METHOD}

We attended a meeting of an agoraphobia self-help group located in a large midwestern city and distributed the questionnaire appearing in Table 1. Forty questionnaires were completed and returned of which 28 were from patients who reported being formally diagnosed as agoraphobic by a mental-health professional. This latter group comprised our sample We have no way of knowing how representative this sample is of group members as a whole. or of agoraphobics in general. Findings from this group mav yield findings which can only be viewed as hypotheses worth subsequent replication with more representative samples of agoraphobics.

\section{RESULTS}

Our 28 respondents had a mean age of $37.5 \mathrm{yr}(\mathrm{SD}=10.7)$ and $25\left(89^{\circ}\right)$ were female. Eighteen had received the diagnosis of agoraphobia from a psychiatrist. 5 from a clinical psychologist. 4 from a psychiatric social worker and 1 from an unspecified mental-health professional. All 28 reported a history of one or more spontaneous panic attacks, with a mean age of onset for thejr first such attack of $25 \mathrm{yr}(\mathrm{SD}=10.8)$, and a mean age of $33 \mathrm{yr}(\mathrm{SD}=10.6)$ for when they first realized the were developing agoraphobia. Using a pairwise $i$-test. this difference is significant at less than the 0.001 level 


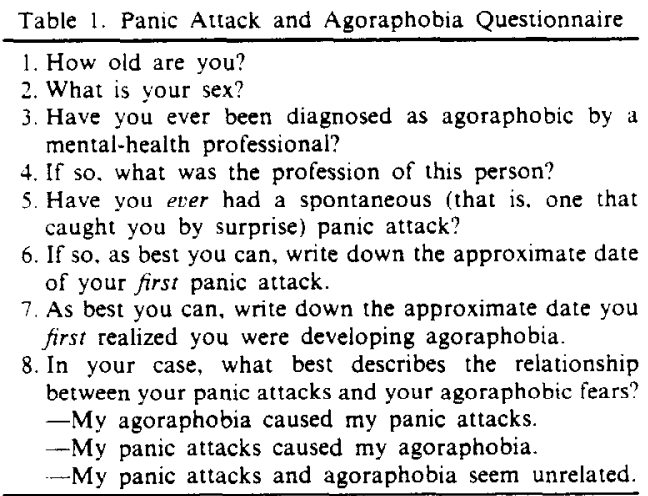

Twenty-two ( $79 \%$ ) endorsed the statement "My panics caused my agoraphobia". five ( $18 \%$ ) believed that "My agoraphobia caused my panic attacks" and one person $(3 \%)$ stated that "My panics and agoraphobia seem unrelated".

\section{DISCUSSION}

Our data seem to replicate the hypothesis that most agoraphobics have a history of panic attacks. More importantly, in our sample the onset of panic attacks preceded the development of agoraphobia by approx. $9 \mathrm{yr}$, and most patients attributed the onset of their agoraphobic symptomatology to their experience of spontaneous panic attacks. These results provide the first empirical support for the early speculations of Freud and for the similar hypotheses recently put forward from Klein (1981) and Sheehan (1982) and adopted by the DSM-III. Given the apparently long latency occurring between the onset of panic attacks and the development of the severe handicaps characteristic of agoraphobia, it would seem that ample opportunity exists for preventative mental-health efforts. Likely therapeutic options for such preventative efforts may be either pharmacological (Sheehan, 1982; Klein, 1981) or behavioral (Marks, 1981) in nature.

Although our data do not address the etiology of spontaneous panic attacks themselves, there is considerable evidence reviewed elsewhere (Curtis, Thyer and Rainey, 1985; Thyer, Nesse, Cameron and Curtis, 1985) supporting a biological etiology for the syndrome. Our data do support a learning-theory explanation for the massive avoidance behavior and anticipatory anxiety characteristic of agoraphobia, in terms of both classically-conditioned anxiety response patterns and intermittant negative reinforcement for avoidance or escape from feared situations.

Correspondence-Requests for reprints should be addressed to B. A. Thyer

\section{REFERENCES}

APA; American Psychiatric Association (1980) Diagnostic and Statistical Manual for Mental Disorders, 3rd edn. APA. Washington, D.C.

Curtis G. C., Thyer B. A. and Rainey J. (1985) Psychiatric Clinics of North America: Anxiery Disorders. Saunders, New York.

Freud S. (1962) Obsessions and phobias. In The Standard Edition of the Complete Psychological Works of Sigmund Freud, Vol. 3 (Edited by Strachey J.), p. 81. Hogarth Press, London (originally published 1894).

Klein D. F. (1981) Anxiety reconceptualized. In Anxiety: New Research and Changing Concepts (Edited by Klein D. F and Rabkin J.). Raven Press, New York.

Marks I. M. (1981) Cure and Care of Neurosis. Wiley, New York.

Mendel J. and Klein D. F. (1969) Anxiety attacks and subsequent agoraphobia. Compreh. Psychiat. 10, 190-195.

Sheehan D. V. (1982) Panic attacks and phobias. New Engl. J. Med. 307, 156-158.

Sheehan D. V. and Sheehan K. E. (1982) The classification of anxiety and hysterical states: Part II. Toward a more heuristic classification. J. clin. Psychopharmac. 2, 386-393.

Thyer B. A., Nesse R. M., Cameron O. G. and Curtis G. C. (1985) Agoraphobia: a test of the separation anxiety hypothesis. Behav. Res. Ther. 23, 75-78.

Thyer B. A., Parrish R., Curtis G. C., Nesse R. M. and Cameron O. G. (1985) Ages of onset of DSM-III anxiety disorders. Compreh. Psychiat. 26, 113-122. 